\title{
Compatibilizer Role of Styrene-butadiene-styrene Triblock Copolymer in Asphalt
}

\author{
Shingo KamiYa, Shigeru TASAKA, Xiaomin ZHANG, \\ Dewen DoNG, and Norihiro INAGAKI \\ Graduate School of Science and Engineering, Shizuoka University, \\ 3-5-1 Johoku, Hamamatsu 432-8561, Japan
}

(Received June 5, 2000; Accepted December 6, 2000)

\begin{abstract}
Polymer modified asphalt (PMA) was prepared from mixtures of triblock copolymer poly (styrenebutadiene-styrene) (SBS) and asphalt. Physical and mechanical properties of the mixtures were characterized by differential scanning calorimeter (DSC), needle penetration and softening point methods, and tensile strength measurement. The glass transition temperatures of both blocks of SBS changed with the fraction of asphalt varied from 0 to $97 \%$, which indicates the mixture system to be partially miscible at least. Maltene, the soluble fraction extracted from the asphalt by $n$-heptane, was found to interact preferentially with the polybutadiene unit of SBS, whereas asphaltene, insoluble fraction interacted predominantly with the polystyrene unit. Fraction dependence of viscosity, penetration and tensile strength of the mixtures showed the threshold at low SBS concentration (e.g., 5-10\%) to increase markedly. A microstructure model for the PMA system with lower SBS is proposed. The small amount of SBS in PMA seem to act as compatibilizer and emulsify the two components of asphalt to make a mechanically stable network.

KEY WORDS Asphaltene / Compatibilizer / Maltene / Polymer Modified Asphalt (PMA) / Styrenebutadiene-styrene Triblock Copolymer (SBS)/
\end{abstract}

Asphalt is a residue of crude oil refining, described as a mixture of a variety of chemical components. ${ }^{1-4} \mathrm{De}-$ spite its complicated components and composition, asphalt is a well-known natural material and widely used. $^{5-6}$ Unfortunately, high temperature rutting and low temperature cracking of asphalt cement or coating layer due to severe temperature susceptibility limits its further application. To resolve the problems, polymer modified asphalt (PMA) was investigated by incorporating natural and synthetic rubbers into asphalt matrix. Among additive rubbers, block copolymers, especially styrenic (ST) copolymer including SBS (styrenebutadiene (BT) -styrene block copolymer), are recognized as effective asphalt modifiers due to thermoplastic elastomeric properties. The glassy ST domains of SBS increase the stiffness of asphalt for high temperature use, whereas the rubbery BT midblocks resist thermal cracking at low service temperatures. These studies reveal remarkable improvement in the properties of conventional asphalt materials, ${ }^{7}$ even by adding a small amount of SBS (e.g., 5-10\%). That SBS becomes a matrix with about $10 \%$ of addition of SBS at the Asphalt/SBS mixtures was confirmed with TEM micrograph. However, due to additional complexity in understanding, designing and producing PMA, high production cost, and in some cases, conflicting reports regarding performance, the development and application of PMA have been limited over the years.

To get structural information about PMA containing SBS, Ho, and co-workers studied the dependence of asphalt components, ${ }^{8}$ simply categorized as two parts of maltene and asphaltene through solvent extraction by $n$ heptane, and the contribution of each part of SBS to the two parts, and concluded small interactions between asphalt and SBS.

This paper discusses phase states in mixtures of asphalt and small amount of SBS. Physical and mechanical properties of the PMA as well as mixture of SBS with maltene and asphaltene were characterized by routine test methods. A microstructural model based on the fundamental properties of PMA is proposed.

\section{EXPERIMENTAL}

\section{Materials}

Straight asphalt was purchased from Showa Shell Petroleum Co. (JIS Penetration 60/80). Maltene and asphaltene were obtained by extraction of the above asphalt by $n$-heptane.

Triblock copolymer SBS was from Shell Co. Japan (KRATON D1101, styrene/butadiene $=31 / 69$ ), and homopolymer polystyrene (HYMAR ST120, average $M_{\mathrm{w}}$ : 10000) from Sanyo Kasei Industry. Asphalt or its component, melted in a stainless cup at $185^{\circ} \mathrm{C}$, was gradually added to preheated SBS or PS. Mechanical mixting was done for $120 \mathrm{~min}$ at $3000 \mathrm{rpm}$ by homomixer (Tokusyukika Co. Ltd. MARK II) at $185^{\circ} \mathrm{C} .{ }^{9}$ The PMA sample was made into a sheet of $1 \mathrm{~mm}$ by hot press and gradually cooled to room temperature.

\section{Measurements}

DSC measurements were conducted with a Mac Science DSC3100 under air atmosphere. To determine glass transitions, PMA samples cooled with liquid nitrogen were heated from $-110^{\circ} \mathrm{C}$ to $120^{\circ} \mathrm{C}$ at a heating rate of $10^{\circ} \mathrm{C} \mathrm{min}-1$. To prevent the influence of physical aging, samples were cooled from $100^{\circ} \mathrm{C}$ without annealing at a specific temperature.

Needle penetration was measured in piercing depth of the needle by the measurement equipment, specified by JIS (K2207). The softing point was measured at a heating rate of $5^{\circ} \mathrm{C} \min ^{-1}$ in glycerine by the Ring \& Ball method, specified by JIS (K2207).

Mechanical properties were measured by JIS (A6021) with tensile speed of $100 \mathrm{~mm} \mathrm{~min}^{-1}$ at $10^{\circ} \mathrm{C}$, and tensile strength and elongation percentage were obtained from 
stress- ${ }^{-}$strain curves plotted by an Auto-graph II of Simadzu Co. Ltd.

To investigate adhesion conditions of the interface between asphalt and SBS, peel test for the two materials coated on aluminum foils was performed by $180^{\circ}$ mode. Two samples with aluminum foil were in contact with a pressure clump $\left(0.1 \mathrm{Kg} \mathrm{cm}^{-2}\right)$ and annealed for $30 \mathrm{~min}$ at various temperatures.

\section{RESULTS AND DISCUSSION}

\section{Thermal Analysis of Modified Asphalt}

DSC was conducted to determine the glass transition temperature $\left(T_{\mathrm{g}}\right)$ of modified asphalt composites. From the standpoint of molecular chain motion, change of $T_{\mathrm{g}}$ is the most direct reflection of compatibility among components of a system.

Figure 1 shows DSC curves of SBS/asphalt mixtures with various compositions. $T_{\mathrm{gs}}$ of polybutadiene (PB) unit of SBS shifted from $-90^{\circ} \mathrm{C}$ to higher temperatures, with increasing asphalt concentration, while $T_{\mathrm{g}}$ of asphalt at $-34^{\circ} \mathrm{C}$ decreased. $T_{\mathrm{g}}$ of the polystyrene unit changed little. This suggests that asphalt consisting of several components are at least partially miscible with $\mathrm{SBS}$. In general, $T_{\mathrm{g}}$ at $-34^{\circ} \mathrm{C}$ of asphalt is attributed to segment motion of the whole maltene fraction. Therefore, the maltene fraction of asphalt seems to interact with the PB unit of SBS. The following experiments were carried out for further information on interactions between two components of asphalt and two block units of SBS.

Styrene homopolymer with molecular weight of $10^{4}$, comparable to that of the polystyrene (PS) unit of SBS, was mixed with asphalt. From DSC curves of the PS/asphalt mixture (Figure 2$), T_{\mathrm{g}}\left(61^{\circ} \mathrm{C}\right)$ of PS shifted to the lower temperature with increasing asphalt concentrations, while the $T_{\mathrm{g}}$ of asphalt at $-34^{\circ} \mathrm{C}$ little changed. This indicates that PS is partially miscible with asphalt and has some interactions with asphalt fractions.

The asphalt can be separated into two components, maltene, and asphaltene, through solvent extraction by $n$-heptane. ${ }^{10-11}$ The insoluble fraction, asphaltene, was a dark-brown brittle glassy solid with $T_{\mathrm{g}}$ about $40-60^{\circ} \mathrm{C}$, and $16 \mathrm{wt} \%$ of the total asphalt. The soluble fraction, maltene, was liquid with high viscosity and lower $T_{\mathrm{g}}$ about $-40^{\circ} \mathrm{C}$, and $84 \mathrm{wt} \%$ of the total asphalt.

Figure 3 shows DSC curves in mixtures of maltene and SBS. $T_{\mathrm{g}}$ of maltene is $-39^{\circ} \mathrm{C}$, as shown in Figure $3 \mathrm{~d}$. With increasing maltene concentration, two $T_{\mathrm{g}} \mathrm{s}$ of SBS changed, especially $T_{\mathrm{g}}$ of $\mathrm{PB}$ unit in $-90^{\circ} \mathrm{C}$ shifted to $-78^{\circ} \mathrm{C}$. The maltene may be fairly miscible with SBS. However, there are some differences for the asphaltene/ SBS system.

Figure 4 shows DSC curves of asphaltene/SBS mixtures. As shown in Figure $4 \mathrm{~d}, T_{\mathrm{g}}$ of asphaltene is $35^{\circ} \mathrm{C}$. $T_{\mathrm{g}}$ of PS unit of SBS decreased with increase of asphaltene fraction, while $T_{\mathrm{g}}$ of asphaltene increased. $T_{\mathrm{g}}$ of PB unit of SBS was nearly unchanged. We could not observe a clear change of $T_{\mathrm{g}}$ for PS unit in Figure 1, because of lower fractions of PS $(<30 \mathrm{wt} \%)$ in the asphalt/SBS mixture. Consequently, asphaltene fraction containing aromatic low molecular weight components was relatively miscible with PS unit of SBS, than PB.

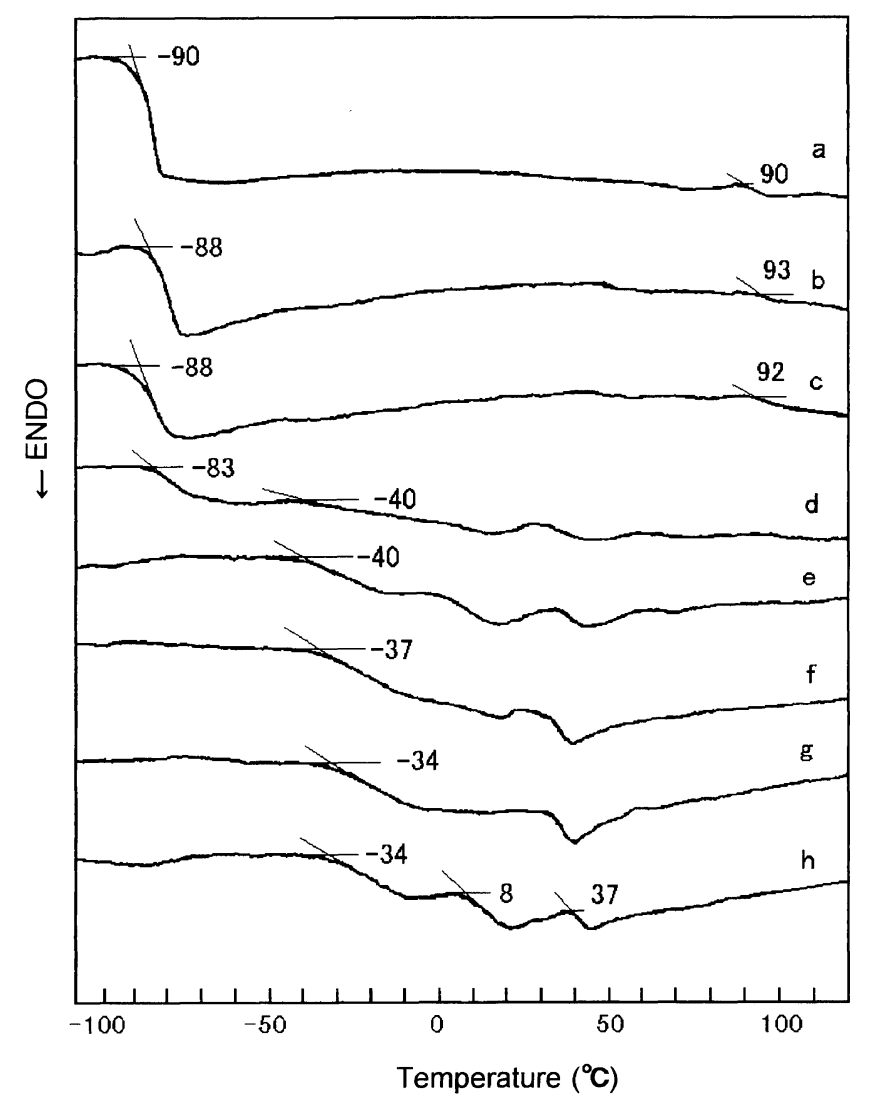

Figure 1. DSC curves of mixtures of SBS and asphalt at heating rate of $10^{\circ} \mathrm{C} \mathrm{min}^{-1}$. a; SBS, b; SBS: Asphalt $=90: 10$, c; SBS: Asphalt $=80: 20$, d; SBS: Asphalt $=50: 50$, e; SBS: Asphalt $=10: 90$, f; SBS: Asphalt=5 : 95, g; SBS: Asphalt=3:97, h; Asphalt.

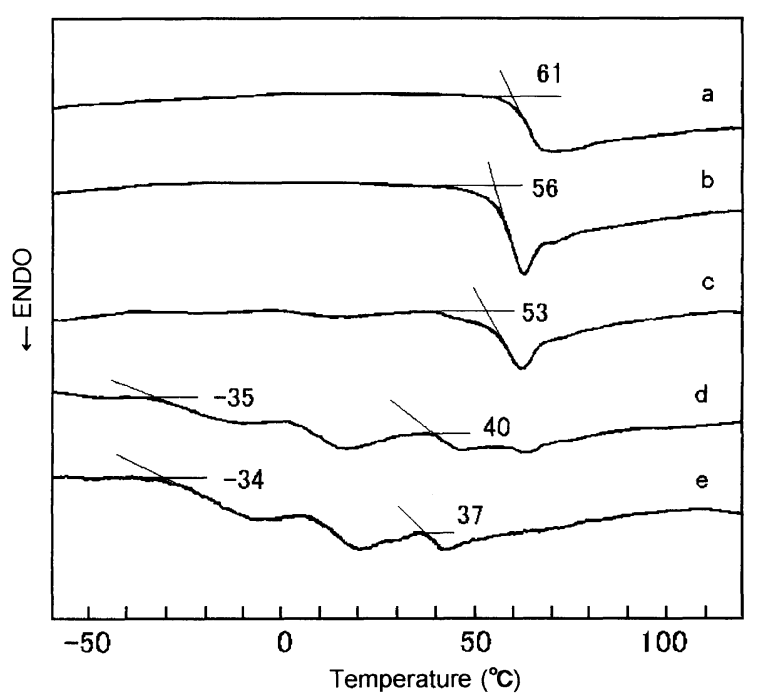

Figure 2. DSC curves of mixtures of PS and asphalt at heating rate of $10^{\circ} \mathrm{C} \mathrm{min}^{-1}$. a; PS, b; PS: Asphalt $=80: 20$, c; PS: Asphalt = $60: 40, d$; PS: Asphalt $=20: 80$, e; Asphalt.

Asphalt was separated into asphaltene and maltene fractions through solvent extraction by $n$-heptane. Each of asphaltene and maltene were not mono fractions of hydrocarbon group. The whole maltene fraction and PB unit may not be compatible. Therefore, change of $T_{\mathrm{g}}$ may not be so large. Change of $T_{\mathrm{g}}$ for the mixture should be attributed only to partial compatibility. 


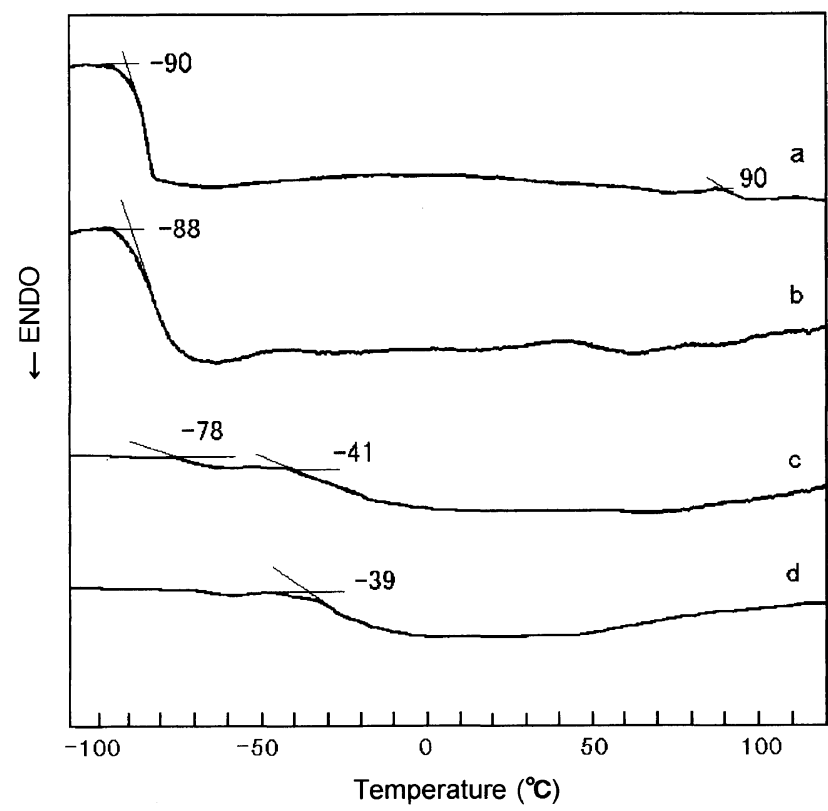

Figure 3. DSC curves of mixtures of SBS and maltene extracted by $n$-heptane at heating rete of $10^{\circ} \mathrm{C} \mathrm{min}^{-1}$. a; SBS, b; SBS: Maltene $=60: 40$, c; SBS: Maltene $=20: 80$, d; Maltene.

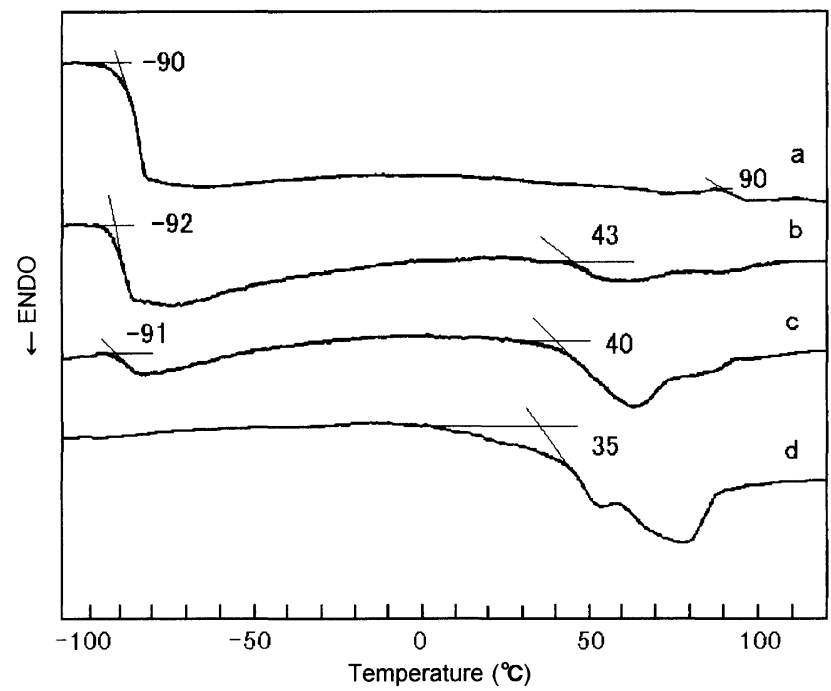

Figure 4. DSC curves of mixtures of SBS and asphaltene extracted by $n$-heptane at heating rete of $10^{\circ} \mathrm{C} \min ^{-1}$. a; SBS, b; SBS: Asphaltene $=60: 40, \mathrm{c}$; SBS: Asphaltene $=20: 80, \mathrm{~d}$; Asphaltene.

\section{Rheological and Mechanical Properties of Modified As- phalt}

Rheological and mechanical properties of SBS modified asphalt were measured by the routine test methods. As shown in Figure 5a, the penetration of samples decreased with SBS concentration, while softening point increased. There is a threshold of softening point during SBS concentration of 5-10 wt\%.

Figure 6 shows the relationship between SBS concentration and tensile strength, as also noted for the softening point. There may exist a critical concentration around which a new phase structure is formed. PMA with more than $10 \%$ of SBS may form a continuous phase of SBS. According to DSC results, asphaltene and
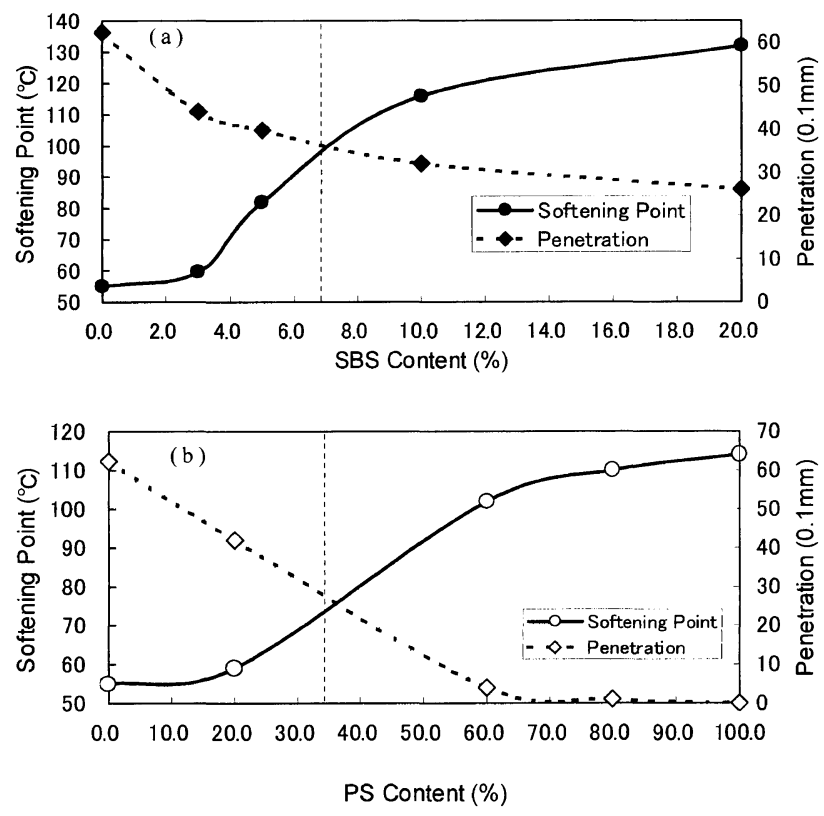

Figure 5. Relationship between SBS content (a) and PS content (b) at softening point and penetration $\left(25^{\circ} \mathrm{C}\right)$.

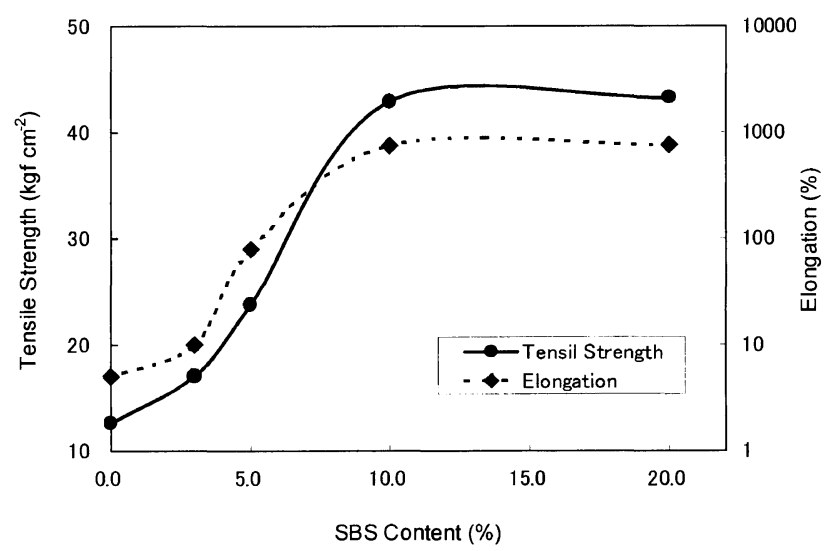

Figure 6. Relationship between tensile strength and elongation with tensile speed of $500 \mathrm{~mm} \mathrm{~min}^{-1}$ at $10^{\circ} \mathrm{C}$ on SBS content.

maltene are partially miscible with SBS. The phase structure may thus change the physical properties of PMA at room temperature.

Figure $5 \mathrm{~b}$ shows the penetration and softening point of asphalt/PS system. Though the asphalt/PS and asphalt/SBS curves are very similar, there is large difference between in the threshold concentration of polymers. The threshold concentration of PS is of $20-30 \mathrm{wt} \%$ in asphalt/PS. A asphalt/PS is a partially miscible system, ${ }^{12}$ so the island structure of PS are connected with each other at more than 20 wt\% of PS in asphalt sea. Apparent phase change is observed in physical properties at about $35 \mathrm{wt} \%$ of PS. This critical concentration at 30 40 vol\% for the phase change is consistent with the percolation threshold in a three dimensional binary system. ${ }^{13}$ This is pure statistical behavior in a binary system without interaction between asphalt and PS. For lowering product cost, the properties of neat asphalt are significantly improved by incorporating SBS even at very low concentration compared with PS/asphalt. 
In mixtures of asphalt and SBS, PS unit/asphaltene, and PB unit/maltene were partially compatible. SBS may thus work as a compatibilizer and a small amount of SBS effectively induces phase inversion of the mixture. PS cannot have a compatibilizer role in asphalt because of interactions only with asphaltene.

\section{Microstructural Model for the Modified Asphalt}

In general, asphaltene is polystructual colloid as dispersed in maltene. Asphalt is essentially an inhomogeneous system. ${ }^{14-15}$ The physical properties of asphalt may depend not only on chemical structures of components but compositions, as well and melt-viscosity should reflect phase structures.

The relationship between melt-viscosity and kneading time was investigated at high temperature. Figure 7 shows the melt-viscosity of SBS/asphalt system as a function of kneading time at $185^{\circ} \mathrm{C}$. PMA containing 3 wt\% SBS has very low melt-viscosity, and viscosity gives no obvious change at this kneading time. PMA containing $10 \mathrm{wt} \%$ SBS exhibits relatively higher melt-viscosity, and melt-viscosity increases linearly to saturation with time. At low SBS of $3 \mathrm{wt} \%$, SBS swelled by and dispersed in asphalt. Only when SBS reached a higher value (e. g., $10 \mathrm{wt} \%$ ), was continuous phase formed. Adequate kneading time is necessary in PMA for interactions between SBS and asphalt. The morphology of PMA seems to depend on amount of SBS and kneading time.

Figure 8 shows peel strength of samples heat-sealed between SBS and asphalt. Peel strength increases with an increase in annealing temperature. We observed coloring in peel fracture surfaces of SBS side above $100^{\circ} \mathrm{C}$ (Figure not shown). This indicates that a component of asphalt diffuses into SBS above $100^{\circ} \mathrm{C}$, the glass transition temperature of polystyrene unit in SBS. Peel strength for annealed sample above $150^{\circ} \mathrm{C}$ was very high because the microphase transition temperature $\left(180^{\circ} \mathrm{C}\right)^{16}$ of polystyrene block makes diffusion of asphalt and SBS easy. At $150-200^{\circ} \mathrm{C}$ for a long time (more than $2 \mathrm{~h}$ ), peel strength decreased very much, due to mechanical brittleness of the asphalt, because its low molecular weight components, especially maltene, diffuse into SBS.

Table I lists solubility parameters of asphalt components as well as SBS blocks. ${ }^{17-18}$ The solubility parameter of maltene is close to that of $\mathrm{PB}$, while the solubility parameter of asphaltene was similar to that of PS. According to the electron micrograph of Nakajima and coworkers, ${ }^{19}$ there are asphalt droplets of less than $1 \mu \mathrm{m}$ into SBS for such PMA. If PMA contains $7 \mathrm{wt} \%$ of SBS at the critical concentration and asphalt droplets are covered with SBS, the thickness of SBS should be less than $20 \mathrm{~nm}$. This thickness is about a half the extended SBS chain. SBS monolayers that act as an additional compatibilizers would form micelles at the interface between asphalt components and SBS.

Generally, large volume ingredient (equal to or more than $75 \%$ ) or lower melting viscosity of ingredient (asphalt in this case) makes matrix phase. If $10 \%$ of SBS forms matrix phase, the following requirement of the viscosity formula by Einstein ${ }^{20}$ is applicable:

$\eta \mathrm{D}$ (Viscosity of disperse phase) / $\eta \mathrm{C}$ (Viscosity of matrix phase) $\geqq 1$

From this formula, the viscosity of matrix phase (SBS)

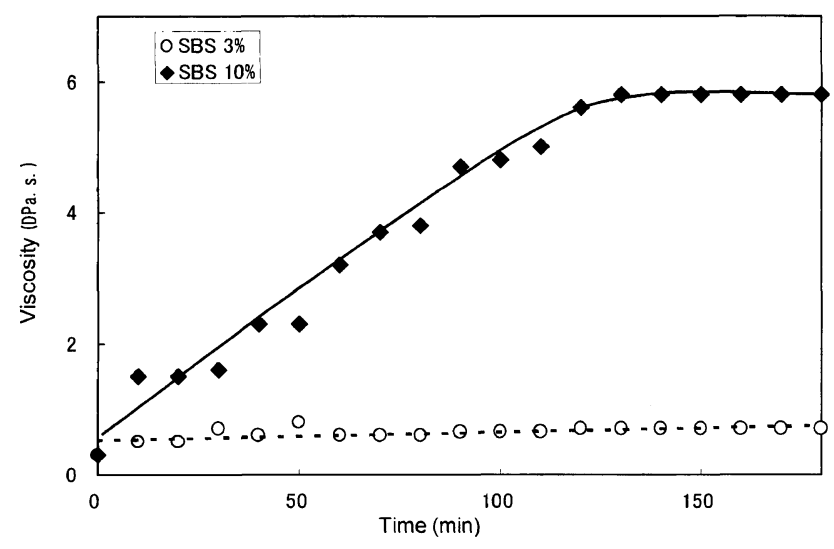

Figure 7. Time dependency of viscosity for mixture of SBS and asphalt at $185^{\circ} \mathrm{C}$

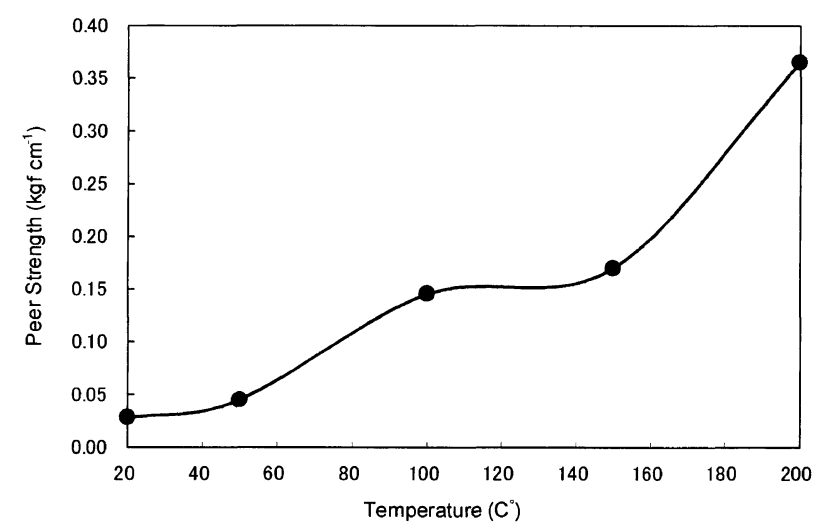

Figure 8. Peel strength of heat-sealed sample between SBS and asphalt as function of annealing temperature for $30 \mathrm{~min}$.

Table I. Solubility parameters of SBS and asphalt

\begin{tabular}{lc}
\hline \multicolumn{1}{c}{ Polymer } & Solubility parameter \\
\hline (Asphalt) & \\
Asphaltene & $8.0-10.0$ \\
Maltene & below 8 \\
(SBS) & 8.0 \\
Polybutadiene & 9.1 \\
Polystyrene & \\
\hline
\end{tabular}

must be lower than that of disperse phase (asphalt). According to actual viscosity data of SBS and asphalt $(0.3$ DPa.s at $185^{\circ} \mathrm{C}$ ), viscosity of SBS is higher than that of asphalt. This formula is in contradiction to the experimental results. Therefore, we should consider a special interaction between SBS and asphalt.

We propose a microstructural model of modified asphalt for SBS mixing to asphalt at $185^{\circ} \mathrm{C}$, as shown in Figure 9. The structure of asphalt is a colloid of two components of asphaltene in maltene (Figure $9 \mathrm{a}$ ). By adding a small amount of SBS to the matrix at high temperature, molecular chains of SBS stay at the interface between asphaltene and maltene, and viscosity increases with preferential interactions of asphaltene with PS units of SBS (Figure 9b). At SBS, less than $5 \mathrm{wt} \%$, favorable interactions between asphaltene and PS unit in SBS and unfavorable interactions between maltene and PS unit may form up unstable micelles. With further ad- 

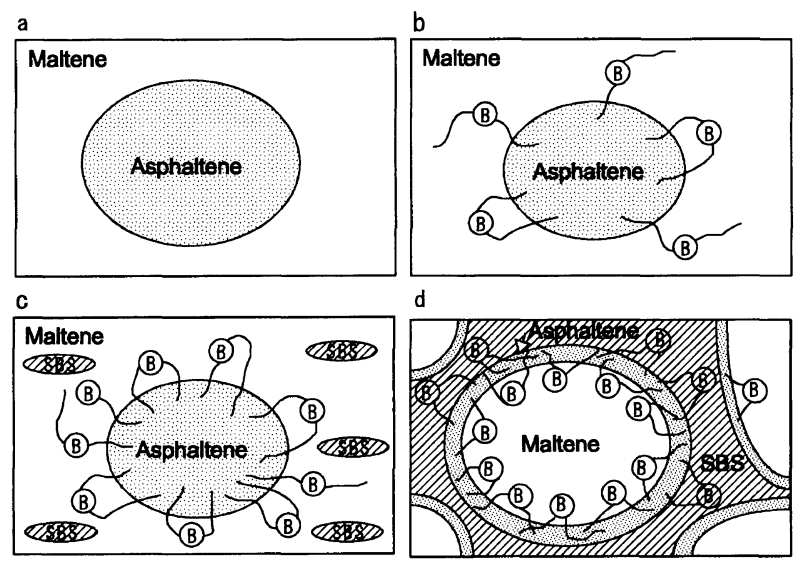

(B) Polybutadiene unit C Polystyrene unit

SBS SBS micell

Figure 9. Schematic model of SBS/asphalt mixtures at 170-185 ${ }^{\circ} \mathrm{C}$. a: Asphalt, b: SBS $(<5 \%) /$ Asphalt, c: SBS (5-8\%)/Asphalt, d: SBS $(>10 \%) /$ Asphalt.

dition, SBS on interface may become saturated, leading to the formation of SBS micelles in the maltene phase (Figure 9c). When SBS reaches a critical value (about 10 wt\%), SBS and the asphaltene phase become a continuous phase by phase inversion (Figure $9 d$ ). When SBS becomes matrix, the system should be stable since the entire interface was occupied by SBS. SBS plays functions of not only emulsifier but mechanical stabilizer. By the model, it is not difficult to understand of PMA.

\section{CONCLUSION}

Polymer modified asphalt with different composition was prepared from triblock copolymer poly(styrenebutadiene-styrene) (SBS) and asphalt. Maltene, the soluble fraction extracted from asphalt by $n$-heptane, interacted preferentially with the polybutadiene unit $(\mathrm{PB})$ of SBS, whereas asphaltene, insoluble fraction, predominantly with the polystyrene (PS) unit from DSC measurement. Rheological and mechanical measurements demonstrated that viscosity, penetration and tensile strength of the composite were enhanced even at low SBS concentration (e.g., between 5-10\%). The compo- nents of asphaltene and maltene partially interacted with specific units of SBS, so that emulsifying effects of SBS resulted in phase inversion. A microstructure model which SBS played as compatibilizer for the PMA system is proposed, which should explain the phenomena.

\section{REFERENCES}

1. G. O'donell, Anal. Chem ., 23, 894 (1951).

2. R. N. Traxler, Oil \& Gas J., 14, 158 (1953).

3. J. G. Speight, in "Asphaltene and Asphalts, 1", T. F. Yen, Ed., Elsevier, Amsterdam, 1994, p 8.

4. R. N. Hubbard and K. E. Stanfield, Anal. Chem., 20, 460 (1948).

5. F. S. Rostler and R. M. White, AAPT, 31, 35 (1962).

6. T. F. Turner and J. F. Branthaver, in "Asphalt Science and Technology”, A. M. Usmani, Ed., Marcel Dekker, Inc., New York, N.Y., 1997, pp 59-101.

7. A. Adedeji, T. Grunfelder, F. S. Bates, C. W. Macosko, M. Stroup-Gardiner, and D. E. Newcomb, Polym. Eng. Sci., 36, 1707 (1996).

8. R. Ho, A. Adedeji, D. W. Giles, D. A. Hajduk, C. W. Macosko, and F. S. Bates, J. Polym. Sci., 35, 2857 (1997).

9. U. Sundararaj, C. W. Macosko, A. Nakayama, and T. Inoue, Poly. Eng. Sci., 35, 100 (1995).

10. H. Tanaka, M. Kawatuki, and K. Takagi, Asphalt, 198, 37 (1999).

11. E. J. Barth, in "Asphalt, science and technology", Gordon and Breach Science, New York, N.Y., 1962, p 117.

12. J. Zielinski, in "Asphalt Science and Technology", A. M. Usmani, Ed., Marcel Dekker, Inc., New York, N.Y., 1997, p 307.

13. H. E. Stanley, in "Real Space Renormalization", T. W. Burkherdt and J. M. J. van Leeuwen, Ed., Springer-Verlag, New York, N.Y., 1982, pp 169-206.

14. E. J. Barth, in "Asphalt, Science and Technology", Gordon and Breach Science, New York, N.Y., 1962, p 10.

15. S. J. Park, J. Escobedo, and, G. A. Mansoori, in "Asphaltene and Asphalts, 1", T. F. Yen, Ed., Elsevier, Amsterdam, 1994, pp $179-205$.

16. R. F. Boyer, "Polymer Yearbook," Harwood Academic Publishers, New York, N.Y., 1985, vol. 2, p 234.

17. Ten Fu Yen, in "Structures and Dynamics of Aspaltenes", O. C. Mulline and E. Y. Sheu, Ed., Plenum Press, New York, N.Y., 1998, p 4.

18. J. B. Gardiner, Rubber Chem. Technol., 43, 370 (1970).

19. S. Nakajima, T. Deguchi, and A. Saitou, J. Rubber Ind. Jpn., 72, 48 (1999).

20. A. Einstein, Ann. Physik, 17, 289, 549 (1905); ibid., 34, 591 (1911). 